\title{
A EDUCAÇÃO MUSICAL NA INTERVENÇÃO PSICOPEDAGÓGICA DAS SÉRIES INICIAIS
}

\author{
Adilce Maria Xavier de Campos ${ }^{1}$ \\ Andreia Menegueti ${ }^{2}$ \\ Astrogilda Silva de Oliveira ${ }^{3}$ \\ Crist Wilian de Moura Barbosa da Silva ${ }^{4}$ \\ Gercina Fabiana Santana Barros 5 \\ Giselle Carolina de Lima e Silva ${ }^{6}$ \\ Jaqueline Miranda de Sena ${ }^{7}$ \\ Luana Xavier Gonçalves de Paula ${ }^{8}$ \\ Rosangela Cristina de Souza Machado9 \\ Uetes do Carmo Santos ${ }^{10}$
}

RESUMO: A aprendizagem encontra-se em foco de discussões psicopedagógicas, buscandose melhoras formas de diagnóstico e de estratégias para se trabalhar junto aos alunos e professores no processo de ensino-aprendizagem. Neste contexto, se apresenta a educação musical para trabalhar a aprendizagem dos alunos da educação básica, embasando-se em uma forma de intervenção psicopedagógica no processo de ensino-aprendizagem. O objetivo geral deste estudo é discutir as potencialidades da educação musical no desenvolvimento da aprendizagem dos alunos da educação básica. Este estudo se qualifica como uma pesquisa bibliográfica. O desenvolvimento deste estudo se embasar na importância de se compreender as potencialidades da educação musical no processo de ensino-aprendizagem dos alunos em sala de aula. A educação musical não se restringe a formação de músicos, mas se constitui também como uma estratégia de ensino para promover a aprendizagem de diversos conhecimentos aos alunos das séries iniciais.

Palavras-chave: Aprendizagem. Intervenção Psicopedagógica. Educação Musical. Música. Estratégia de Ensino.

\footnotetext{
'Licenciada em Pedagogia pela Faculdade de Filosofia, Ciências e Letras de Jales. Pós-graduada pelo Instituto Educacional de Assis IEDA. Faculdade de Educação de Assis - Didática Geral. e-mail: adilce.campos@hotmail.com.

${ }^{2}$ Especialista em Educação Física pela Universidade Cândido Mendes - Rio de Janeiro. Graduada em Educação Física Licenciatura pela Universidade Cuiabá - UNIC. Professora efetiva da rede pública municipal de Cuiabá-MT. e-mail: andreiamenegueti978@gmail.com.

${ }^{3}$ Concluído em 1998 pela Universidade de Cuiabá - UNIC o curso de Pedagogia - Licenciatura Plena. Pós-Graduação em 2020 pela Faculdade de Educação São Luís o curso de Educação Especial e Inclusiva. e-mail: astrogildasilvaio@gmail.com.

${ }^{4}$ Pós-graduado em Docência do Ensino Superior pela Faculdade Brasileira de Educação e Cultura. Pós-graduado em Atendimento Educacional Especializado pela Faculdade de Administração, Humanas e Exatas. Licenciado em Geografia pela UNIP. Licenciado em Pedagogia pela Faculdade Delta. e-mail: cristwilian@hotmail.com.

5 Graduada em Licenciatura Plena em Pedagogia pela UNIC. Pós-graduada em Educação Infantil e Alfabetização pelo ICEC. e-mail: barrosfabiana2ı2@gmail.com.

${ }^{6}$ Licenciada em Pedagogia pela UNOPAR. Especialista em Educação Infantil com ênfase em letramento pela FACITEP. E-mail: gi.lima3@hotmail.com.

${ }_{7}^{7}$ Licenciatura em Pedagogia pela UFMT - Universidade Federal de Mato Grosso. Pós-graduada em Educação Infantil pela AVEC Associação Varzeagrandense de Ensino e Cultura.e-mail: jaque_sena@hotmail.com.

${ }^{8}$ Licenciatura em Pedagogia - UNOPAR. Pós-graduada em psicopedagogia - UNIASSELVI.e-mail: depailaluana765@gmail.com.

${ }_{9}$ Graduada em Pedagogia pela UNIVAG - Centro Universitário de Várzea Grande. Especialista em Educação Infantil e Alfabetização pela FIAVEC - Faculdades Integradas de Várzea Grande. e-mail: rosangelacsm@gmaill.com.

${ }^{\text {to }}$ Pós-graduado em Educação Infantil e Ensino Fundamental (UNIP-DF). Pós-graduado em Docência do Ensino Superior pela Faculdade de Ciências de Wenceslau Braz (FACIBRA). Licenciado em Educação Física pela Universidade Paulista (UNIP). e-mail: pefprofessor@gmail.com.
} 
ABSTRACT: Learning is the focus of psychopedagogical discussions, seeking better forms of diagnosis and strategies to work with students and teachers in the teaching-learning process. In this context, music education is presented to work on the learning of basic education students, based on a form of psychopedagogical intervention in the teachinglearning process. The general objective of this study is to discuss the potential of music education in the development of learning for students in basic education. This study qualifies as a bibliographic research. The development of this study is based on the importance of understanding the potential of music education in the teaching-learning process of students in the classroom. Music education is not restricted to the training of musicians, but it is also a teaching strategy to promote the learning of diverse knowledge to initial series students.

Keywords: Learning. Psychopedagogical Intervention. Musical education. Song. Teaching Strategy.

\section{INTRODUÇÃO}

A aprendizagem encontra-se em foco de discussões psicopedagógicas, buscando-se melhoras formas de diagnóstico e de estratégias para se trabalhar junto aos alunos e professores no processo de ensino-aprendizagem. O processo de ensino-aprendizagem se constitui complexo pela influência de diversos fatores internos e externos, que devem ser considerados por psicopedagogos e professores para definirem o planejamento dos caminhos da aprendizagem dos alunos da educação básica.

A análise psicopedagógica fomenta o planejamento do processo de ensinoaprendizagem, contemplando o trabalho com as dificuldades de aprendizagem que são apresentadas pelos alunos em sala de aula. Neste contexto, se apresenta a educação musical para trabalhar a aprendizagem dos alunos da educação básica, embasando-se em uma forma de intervenção psicopedagógica no processo de ensino-aprendizagem. Desta maneira, apresenta-se a questão que norteou o desenvolvimento deste estudo: Como trabalhar as potencialidades da educação musical para a promoção da aprendizagem dos alunos?

O objetivo geral deste estudo é discutir as potencialidades da educação musical no desenvolvimento da aprendizagem dos alunos da educação básica. Os objetivos específicos são os seguintes: contextualizar os aspectos do desenvolvimento da aprendizagem no ambiente escolar; abordar sobre a educação musical e seus elementos; e refletir sobre a educação musical como instrumento da intervenção psicopedagógica no desenvolvimento da aprendizagem dos alunos. 
O desenvolvimento deste estudo se embasar na importância de se compreender as potencialidades da educação musical no processo de ensino-aprendizagem dos alunos em sala de aula. O conhecimento psicopedagógico proporciona bases para se discutir diversos tipos de estratégias de ensino e recursos didáticos que fomentam as práticas pedagógicas que são desenvolvidas no processo de ensino-aprendizagem. As discussões possibilitam elencar a abordagem e posição de diversos autores sobre o tema, contribuindo para a sua reflexão e maior compreensão, para se trabalhar o aprimoramento dos caminhos de aprendizagem dos alunos.

Este estudo se qualifica como uma pesquisa bibliográfica, fomentada pelas abordagens levantadas em artigos científicos, livros, monografias, dissertações de Mestrado e teses de Doutorado. Inicialmente, contextualizou-se a aprendizagem no ambiente escolar, com enfoque nos alunos e no processo de ensino-aprendizagem. Sequencialmente, abordouse sobre o desenvolvimento da educação musical e os seus elementos no processo de ensinoaprendizagem. Finalmente, refletiu-se sobre a educação musical como instrumento da intervenção psicopedagógica no desenvolvimento da aprendizagem dos alunos.

\section{O Psicopedagogo e aprendizagem escolar nas séries iniciais}

As séries iniciais se constituem como um campo de atuação do psicopedagogo, promovendo diversas atividades relacionadas ao desenvolvimento dos alunos. Pontes (2010) ressalta que a atuação do psicopedagogo na escola envolve um trabalho de aspecto preventivo e de assessoramento no ambiente educativo.

Campagnolo e Marquezan (2019) salientam que o trabalho psicopedagógico se apresenta necessário ao contexto escolar, mas a sua condição de profissão relativamente nova, potencializando-se confusões e dificuldades na delimitação do seu campo de atuação e na identificação das suas práticas profissionais. Os referidos autores indicam também a carência de uma legislação norteadora da regulamentação do trabalho do psicopedagogo institucional, principalmente por ser esta uma profissão nova no contexto escolar. Além disso, o psicopedagogo deve pensar sobre os fatores internos e externos que influenciam a sua atuação na escola.

Vercelli (2012) aponta a importância de o psicopedagogo trabalhar terapeuticamente as questões referentes à sua aprendizagem, para o exercício profissional adequado, sem a construção de influências problemáticas. $O$ trabalho do psicopedagogo proporciona uma 
base de apoio ao desenvolvimento da mediação do processo de ensino-aprendizagem, realizada pelo professor.

Pontes (2010) aponta a demanda por tirar o professor de uma posição que o considera como transmissor de informação, inclusive adotada por vários docentes brasileiros. A referida autora observa a necessidade de se preencher as lacunas de formação do professor, sem uso de receitas prontas, mas por meio de formação continuada com enfoque no professor na condição de sujeito pensante e desejante.

O trabalho do psicopedagogo proporciona bases para o professor sair da posição de transmissor de informação, para um mediador da construção do conhecimento no processo de ensino-aprendizagem. Vercelli (2012) enfatiza que o psicopedagogo deve orientar o professor com a finalidade de identificar as melhores práticas de apoiar a criança que possui dificuldade de aprendizagem. A referida autora complementa que o psicopedagogo pode realizar encaminhamentos dos alunos para outros profissionais, após esgotadas as possibilidades de intervenção escolar.

Vercelli (2012) salienta que o psicopedagogo tem a função de desenvolver o diagnóstico institucional, para identificação das questões problemáticas questão influenciando o processo de ensino-aprendizagem dos alunos. A referida autora ressalva que muitas vezes o professor não identifica a discordância entre a forma de ensino e a forma da criança aprender. $\mathrm{O}$ olhar externo do psicopedagogo potencializa-se agregador ao trabalho do professor no aprimoramento das práticas pedagógicas aplicadas no processo de ensinoaprendizagem.

Pontes (2010) destaca a inexistência de fórmulas mágicas para se vencer as dificuldades de aprendizagem dos alunos, sendo que estas são sintomas de algo que não vai bem. A referida autora visualiza que o psicopedagogo vai trabalhar de forma preventiva na elaboração do diagnóstico e no trabalho em conjunto com outros agentes escolares, para detectar as dificuldades de aprendizagem, anteriormente à instalação dos processos.

O psicopedagogo precisa desenvolver as habilidades e competências necessárias em seu trabalho, principalmente para lidar com a diversidade de atores escolares e suas respectivas culturas e comportamentos. Campagnolo e Marquezan (2019) observam que o trabalho psicopedagogo perpassa por diversos atores escolares com um olhar sensível às possíveis inquietações que tendem a dificultar a aprendizagem da criança. Além da ação de analisar, o ato de ouvir é fundamental para o psicopedagogo desenvolver a avaliação da 
aprendizagem dos alunos, pois esta atividade envolve ouvir alunos, professores, familiares, demais profissionais da escola e sociedade.

Pontes (2010) visualiza que o psicopedagogo deve se permitir sair da acomodação, para questionar sobre os anseios e as expectativas sobre a sua formação, ao seu trabalho e a sua vida. De acordo com a autora, o olhar psicopedagógico deve estar direcionado à individualidade do aluno, bem como a sua posição na coletividade. Este olhar do psicopedagogo deve estar contemplado nos pareceres de avaliação da aprendizagem dos alunos, demonstrando os caminhos para desenvolver uma aprendizagem significativa, lidando com as dificuldades potenciais e identificadas.

Campagnolo e Marquezan (2019) observam que o psicopedagogo observa e avalia o decorrente na escola, mas sem o objetivo de criticar e indicar erros, mas visando a identificação de metodologias e das práticas pedagógicas, que possibilitem a prevenção de eventuais problemas, transtornos ou dificuldades de aprendizagem. Estes aspectos estão presentes no processo de aprendizagem que contemplam os alunos das séries iniciais.

A aprendizagem se constitui um importante componente de construção do indivíduo e de sua formação, passando pelo seu desenvolvimento no ambiente escolar. Gaspar et al. (2020) ressaltam que a escola fornece um contexto de socialização em que os alunos são capazes de aprender um conjunto de competências, parte delas associadas ao desempenho e sucesso escolares, e ainda se constitui um ambiente exclusivo em que o bem-estar social e emocional dos alunos pode ser desenvolvido.

No ambiente escolar, a aprendizagem dos alunos é trabalhada diariamente, buscandose identificar formas organizadas e sistematizadas para desenvolvê-la no processo de ensinoaprendizagem. Neves (2019) visualiza que o aprendizado proporciona a evolução do indivíduo e do seu próprio desejo ou demanda por aprender, com abrangência de experiências educativas, de construção e expressão de sentidos referentes às aprendizagens construídas.

Souza (2018) aborda que a aprendizagem envolve uma variedade de processos pelos quais os alunos aprendem, independentemente da sua origem ou da forma de ocorrência. A referida autora contempla que não existe maneira correta ou errada de aquisição de conhecimentos, mas correm diferentes formas relacionadas ao resultado almejado, a forma de trabalho, as relações que se deseja desenvolver com o mundo, e entre outros aspectos. Esta constatação demonstra a existência de uma liberdade para se trabalhar os processos e 
elementos que envolvem as estratégias por meio das práticas pedagógicas, que podem ser continuamente renovadas.

O desenvolvimento da aprendizagem envolve processos que passam por mudanças contínuas, inclusive no ato de ensinar, para atendimento das demandas de aprendizado dos alunos na educação básica. De acordo com Zerbato e Mendes (2018) salientam que as mudanças no ato de ensinar envolvem um trabalho de execução difícil, demanda-se uma rede de profissionais de apoio, recursos suficientes, formação e outros componentes necessários para a concretização de um ensino de qualidade.

Gonçalves (2006) complementa que a prática pedagógica é um desafio no cotidiano escolar, pois demanda conhecimentos diversificados dos professores, e assim mais informações sobre o aluno e as demandas concretas de aprendizagem. Neves (2019) aborda que a relação pedagógica é fomentada por um conjunto de percepções e de representações das pessoas que convivem no espaço de aprendizagem e em um determinado momento. As práticas pedagógicas se desenvolvem por meio destas relações no ambiente escolar.

O desenho universal para a aprendizagem se utiliza de conhecimentos científicos para direcionarem o planejamento do processo de ensino-aprendizagem, definindo-se as estratégias de ensino, metodologias, recursos didáticos e demais componentes. De acordo com Nelson (2013), o desenho universal para a aprendizagem se constitui pelos seguintes princípios: a aprendizagem possui relação com os componentes emocionais e biológicos do indivíduo; a essencialidade de experiências significativas aos alunos; a importância das emoções na motivação do aluno; a importância do ambiente; a aprendizagem deve ser significativa para o aluno; cada indivíduo é único; a aprendizagem é aprimorada com desafios e inibida com ameaças.

A construção da aprendizagem passa pela definição e implementação de estratégias articuladas e sistematizadas em contexto de planejamento do processo de ensinoaprendizagem. Boruchovitch (2007) destaca dois tipos de estratégias de aprendizagem: a cognitiva, que se relaciona à execução de atividades que promovem o conhecimento, por meio de uma apropriação baseada na organização e na memória; e metacognitiva, que se relaciona ao aprender a aprender, identificando-se a melhor forma de resolver a situaçãoproblema. Estas estratégias podem ser aplicadas de uma forma geral na aprendizagem escolar, sendo necessário o alinhamento com os objetivos do processo de ensinoaprendizagem. 
Darroz, Travisan e Rosa (2018) destacam que a forma como os alunos se estrutura para aprender se constitui entre os fatores mais decisivos na aprendizagem e no sucesso escolar. Os referidos autores complementam que os professores devem considerar na prática pedagógica a forma como os alunos aprendem em sala de aula, buscando-se caminhos de qualificação do processo de aprendizagem embasadas na revisão e adoção de novas concepções de aprender.

\section{EDUCAÇÃO MUSICAL}

A educação musical se apresenta interdisciplinar e integrada no processo de ensinoaprendizagem, possibilitando a abordagem de conteúdos de diversas disciplinas, facilitando a aprendizagem dos alunos no ambiente escolar. Gonçalves e Pederiva (2019) ressaltam que as experiências musicais são oportunizadas pela musicalidade social presente durante a vida do indivíduo, com a internalização das funções psicológicas superiores identificadas em sua cultura. Os referidos autores contemplam que a musicalidade social é internalizada por meio do desenvolvimento da percepção, da atenção voluntária, da fala, da memória, do pensamento conceitual. A musicalidade social deve ser contemplada no uso da música como recurso didático por meio de uma atividade componente da estratégia de ensino.

Gonçalves (2017) visualiza que a essência da educação musical se encontra identificada na indissociabilidade da unidade dialética educação-música. Vigotsky (2oro) identifica o professor como um organizador do espaço social, pois regula o ambiente com a intenção de criar condições de possibilidades para os estudantes desenvolverem a sua imaginação e a sua liberdade. O professor pode utilizar a educação musical para promover a imaginação e a liberdade dos alunos, usufruindo de suas capacidades e potencialidades como estratégia de ensino no processo de ensino-aprendizagem.

A educação musical pode contemplar um cunho histórico-cultural, inclusive compartilhando as vivências musicais do indivíduo que dialogam com as experiências culturais dos alunos, durante o processo histórico. Gonçalves (2017) aborda que a educação musical histórico-cultural favorece um amplo desenvolvimento da musicalidade no aluno em sua condição social, pois considera as suas vivências musicais únicas, irrepetíveis e intransponíveis. As vivências musicais proporcionam condições que oportunizam outras vivências dentro da musicalidade, agregando também conhecimentos em sua formação. 
Gonçalves e Pederiva (2019) enfatizam que a educação musical histórico-cultural, fundamentada na abordagem de Vygotsky, prima pela suprema importância do social no processo de constituição musical da pessoa e mantém o professor como organizador do espaço social educativo. Os referidos autores ressalvam que os alunos e os professores são seres de relações, constituindo um ato pedagógico relacional. A abordagem histórico-cultural condiciona a educação musical como uma oportunidade formação do aluno como ser social e, consequentemente, cidadão.

Barbosa (2019) observou que a educação musical demanda urgentemente por propostas didático-metodológicas, para garantir presença nas escolas regulares e, consequentemente, mudar de um cenário presença débil no processo educacional. A referida autora contempla que as propostas não representam um método acabado, pois os métodos são construídos em processo dialético de reflexão e prática.

Arruda, Gonçalves Júnior e Costa (2018) identificam a abordagem humanizadora na educação musical, que consiste na busca contínua de conhecimentos e habilidades, interação criativa e cooperativa na convivência das diversas culturas. Os referidos autores salientam que a educação musical humanizadora facilita o acesso à música e a compreensão das múltiplas dimensões e relações da música com a política, a arte e a história. Demore (2019) ressalta que a abordagem humanizadora envolve um processo em constante mudanças, incluindo as concepções do professor, como sensibilidade, solidariedade, compaixão, dialogicidade, preparação da aula e atuação docente. A abordagem humanizadora se constitui uma outra opção de métodos de construção da aprendizagem do aluno na educação musical.

$\mathrm{Na}$ educação musical, a abordagem humanizada possui proximidades com a abordagem histórico-cultural, contribuindo para a formação social e cidadã dos alunos. Demore (2019) salienta que a compreensão e vivência na abordagem da educação musical humanizadora contribui para os educandos se tornarem seres mais conscientes, críticos e preparados para lidarem com a complexidade de sua existência.

Paiva (2017) indica que a tecnologização da educação musical se torna negativa quando se constitui somente como uma informatização acrítica, pois limita as suas diversas possibilidades proporcionadas pelas tecnologias nos âmbitos do ensino e aprendizagem da música. O referido autor contempla que as tecnologias devem ser utilizadas com criticidade e criatividade na educação musical, direcionadas para apoiar a produção do conhecimento. Considerada esta abordagem, identifica-se a potencialidade da educação musical na 
intervenção psicopedagógica em contribuir na promoção da aprendizagem no contexto escolar.

\section{EDUCAÇÃO MUSICAL NA INTERVENÇÃO PSICOPEDAGÓGICA}

As potencialidades da educação musical contribuíram para esta estratégia de ensino ser utilizada na intervenção psicopedagógica realizada juntos alunos da educação básica. Damasceno e Silva Júnior (2018) visualizam a música como uma atividade lúdica, com capacidades de proporcionar o prazer, interesse e ainda potencializar a criatividade, a interação social e a comunicação, em sala de aula e na intervenção psicopedagógica.

Silva (2020) visualiza a escola como uma construção social, que se define a partir das experiências com o mundo, um lugar onde o ensino de música precisa ser consolidado, por meio de uma atuação segura e defesa da educação musical na escola de educação básica. A intervenção psicopedagógica no aprendizado pode se utilizar de diversos caminhos propostos na educação musical, mas demanda-se observar os diagnósticos e os objetivos que envolvem as atividades, com objetivo da promoção da aprendizagem e do desenvolvimento global dos alunos.

Damasceno e Silva Júnior (2018) ressalvam que se a música não for empregada de forma condizente com os objetivos do processo de ensino-aprendizagem, potencializa-se um efeito reverso e constitui mais uma atividade enfadonha que leva a criança a visualizar que o lado bom da escola é o lado de fora. Os referidos autores enfatizam que o objetivo da música no atendimento psicopedagógico é auxiliar os alunos em se tornarem conscientes de si na condição de seres sociais, ampliando as potencialidades e reduzindo os déficits de aprendizagem. Após definidos os objetivos do atendimento psicopedagógico em relação ao recurso didático da música, pensa-se nos caminhos de sua utilização no processo de ensinoaprendizagem.

Akoschky (2015) defende a incorporação de ruídos e de novos instrumentos emissores deles, pois possibilitam a ampliação dos caminhos de acessibilidade da educação musical por meio da exploração sonora e instrumental, acompanhada da representação da escuta decorrente de novas formas gráficas, menos simbólicas e mais aproximadas do objeto. A referida autora complementa que a expansão dos limites sonoros oportuniza o aprendizado sobre as propriedades de novos instrumentos musicais, objetos e materiais do cotidiano. 
Vanzela, Oliveira e Carvalho (2017) observam que a educação musical demanda o desenvolvimento de habilidades cognitivas e exercícios motores, abrangendo a conciliação do lado criativo e a compreensão das linhas melódicas, além de se utilizar das bases técnicas. Os referidos autores visualizam que a aplicação do conhecimento psicopedagógico auxilia os alunos na obtenção de uma performance musical em conformidade com os objetivos do processo de ensino-aprendizagem, considerando o lado pessoal e humano dos alunos, para contemplar a integral e o respeito da identidade deles. A abordagem da educação musical no processo de ensino-aprendizagem não se restringe aos conhecimentos psicopedagógicos e nem aos conhecimentos disciplinares e da música, mas passa pela interdisciplinaridade aplicada na intervenção psicopedagógica direcionada à aprendizagem dos alunos.

\section{CONSIDERAÇÕES FINAIS}

A aprendizagem é o enfoque do trabalho ambiente escolar, em decorrência da sua importância no desenvolvimento global do indivíduo. $O$ desenvolvimento da apresenta complexa, pois envolve um amplo conjunto de processos diversificados em sua construção, passando pela influência de fatores internos e externos. O professor possui o desafio de promover e mediar estratégias de ensino que atendam as demandas por aprendizagem dos alunos no ambiente escolar. Observa-se a existência de diversas formas de se desenvolver a aprendizagem, que observam as individualidades e coletividade presentes em sala de aula. Apesar disso, a aprendizagem se condiciona à compreensão particular em relação ao mundo.

$\mathrm{O}$ ato de ensinar passando por mudanças constantes, em prol do desenvolvimento da aprendizagem em sala de aula. Estas mudanças envolvem a construção e a reconstrução de práticas pedagógicas aplicadas no desenvolvimento dos processos de ensino-aprendizagem da educação básica, influenciadas pelas relações pedagógicas desenvolvidas no ambiente escolar. Entre os diversos aspectos da aprendizagem, destaca-se a estrutura do aluno para desenvolvê-la no contexto escolar. A educação musical oportuniza diversas situações de construção da aprendizagem.

As experiências musicais são construídas com embasamento na musicalidade social e na internalização das funções psicológicas superiores identificadas em sua cultura. $\mathrm{O}$ ambiente escolar é organizado pelos professores, para os alunos desenvolverem a imaginação e liberdade, que são aspectos a serem observados no desenvolvimento da educação musical. A educação musical histórico-cultural beneficia um amplo desenvolvimento da 
musicalidade no aluno em sua condição social, por meio da compreensão de suas vivências sociais, musicais e culturais. $\mathrm{O}$ ato relacional pedagógico congrega todas estas vivências, para a formação de uma aprendizagem abrangente de diversos conhecimentos pelos alunos. A abordagem humanizada trabalha e enfatiza diversas características do indivíduo, que contribuem para a formação de um ser crítico e reflexivo.

As tecnologias são recursos de apoio ao desenvolvimento da produção de conhecimento na educação musical, observando a criticidade e a criatividade. A música poder ser trabalhada como uma atividade lúdica, que proporciona prazer, interesse, criatividade, interação social e comunicação. Os conhecimentos psicopedagógicos auxiliam o professor selecionar a proposta didático-metodológico mais adequada ao desenvolvimento da aprendizagem dos alunos. No atendimento psicopedagógico, a música deve ser empregada para apoiar o aluno na sua compreensão e na sua conscientização como ser social, pois o enfoque não é a formação de um músico, mas ampliar as potencialidades e reduzir os déficits de aprendizagem. A intervenção psicopedagógica respeita a integralidade e a identidade dos alunos, utilizando-se da educação musical para promover a aprendizagem significativa dos alunos.

Desta maneira, conclui-se que a educação musical não se restringe a formação de músicos, mas se constitui também como uma estratégia de ensino para promover a aprendizagem de diversos conhecimentos aos alunos das séries iniciais. $\mathrm{Na}$ abordagem $\mathrm{da}$ intervenção psicopedagógica, a atividade da música valoriza a integralidade e a identidade dos alunos, para atender as demandas de aprendizagem dos alunos das séries iniciais. As potencialidades da educação encontram-se identificadas no desenvolvimento da aprendizagem dos alunos, mas demanda-se o embasamento nos objetivos do processo de ensino-aprendizagem e no diagnóstico do atendimento psicopedagógico.

Considerados estes aspectos, sugere-se o desenvolvimento de um estudo sobre a importância do diagnóstico psicopedagógico para utilizar a música como recurso didático nas estratégias de ensino e aprendizagem. Esta sugestão de estudo é embasada no aprofundamento do tema abordado nesta pesquisa. 


\section{REFERÊNCIAS BIBLIOGRÁFICAS}

AKOSCHKY, Judith. Desde a exploración sonora de cotidiáfonos à la síntesis acústica: processos creativos em educación musical. In: SILVA, H. L. da; ZILLE, J. A. B. (Org.). Música e educação. Barbacena: EdUEMG, 2015. Série Diálogos com o Som. v. 2. p.79-94.

ARRUDA, Murilo Ferreira Velho; GONÇALVES JUNIOR, Luiz; COSTA, Bruna Fuentes. Educação musical humanizadora em um projeto de extensão: desvelando processos educativos. Revista Brasileira de Extensão Universitária, v. 9, n. 3, p. 165-172, 2018. Disponível em: 〈https://periodicos.uffs.edu.br/index.php/RBEU/ article/view/7747>. Acesso em I7 de novembro de 2021.

BARBOSA, Maria Flávia Silveira. Vigotski e Psicologia da Arte: horizontes para a educação musical. Cadernos Cedes, v. 39, p. 31-44, 2019. Disponível em: 〈https:// www.scielo.br/j/ccedes/a/sdRzmVySwGLpBMQR83yF4Tg/abstract/?lang=pt $>$. Acesso em 17 de novembro de 2021.

BORUCHOVITCH, Evely. Aprender a aprender: propostas de intervenção em estratégias de aprendizagem. ETD - Educação Temática Digital, v. 8, n. 2, p. 156-167, 2007. Disponível em: 〈http://repositorio.unicamp.br/handle/REPOSIP/ I18996〉. Acesso em I7 de novembro de 2021.

CAMPAGNOLO, Camila; MARQUEZAN, Fernanda Figueira. A atuação do psicopedagogo na escola: um estudo do tipo estado do conhecimento. Revista Psicopedagogia, v. 36, n. III, p. 34I-35I, 2019. Disponível em: <http://pepsic. bvsalud.org/scielo.php?script=sci_arttext\&pid=Soro3-84862019000400009>. Acesso em 17 de novembro de 202I.

DAMASCENO, Eidson Lima; SILVA JÚNIOR, Edivaldo Xavier. A música como instrumento de intervenção psicopedagógica em crianças com transtorno do espectro autista. Cadernos de Cultura e Ciência, v. 17, n. 2, p. 13-24, 2018. Disponível em: 
<https://www.researchgate.net/profile/Eidson-Damasceno-2/publication/335413376_ A_MUSICA_COMO_INSTRUMENTO_DE_INTERVENCAO_PSICOPEDAGOGIC A_EM_CRIANCAS_COM_TRANSTORNO_DO_ESPECTRO_AUTISTA/links/sesfo

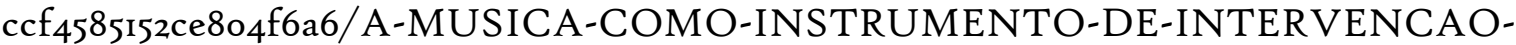
PSICOPEDAGOGICA-EM-CRIANCAS-COM-TRANSTORNO-DO-ESPECTROAUTISTA.pdf $>$. Acesso em i7 de novembro de 2021.

DARROZ, Luiz Marcelo; TREVISAN, Thais Lourençato; ROSA, Cleci Teresinha Werner. Estratégias de aprendizagem: caminhos para o sucesso escolar. Amazônia: Revista de Educação em Ciências e Matemáticas, v. I4, n. 29, p. 93-ı09, 2018. Disponível em: <http://novoperiodicos.ufpa.br/periodicos/index.php/revistaamazonia/ article/view/5473>. Acesso em I7 de novembro de 2021.

DEMORE, Givas. Educação musical e humanização: a educação humanizadora como mediadora do processo de aprendizagem. Revista Lumen, v. 4, n. 8, 2019. Disponível em: $\langle$ http://45.79.222.7I/index.php/lumen/article/view/133〉. Acesso em I7 de novembro de 2021.

GASPAR, Tania et al. Ecossistemas de aprendizagem e bem-estar: factores que influenciam o sucesso escolar. Psicologia, Saúde and Doenças, v. 2I, n. 02, p. 462-48I, 2020. Disponível em: 〈https://repositorio.ul.pt/handle/1045I/444I2 >. Acesso em I7 de novembro de 202I.

GONÇALVES, Aline Kelly Scalco. Estratégias pedagógicas inclusivas para crianças com paralisia cerebral na educação infantil. 2006.136f. Dissertação de Mestrado. Universidade Federal de São Carlos, São Carlos/SP.

GONÇALVES, Augusto Charan Alves Barbosa. Educação musical na perspectiva histórico-cultural de Vigotski: a unidade educação-música. 2017. 277f. Tese (Doutorado em Educação) - Programa de Pós-Graduação em Educação, Faculdade de Educação, Universidade de Brasília, Brasília, 2017.

GONÇALVES, Augusto Charan Alves Barbosa; PEDERIVA, Patrícia Lima Martins. A Unidade educação-música: educação musical na teoria histórico-cultural. Cadernos 
CEDES, v. 39, p. 19-30, 2019. Disponível em: 〈https://www.scielo.br/j/ccedes/a/ tJDwM4wd8PkfFGbJSSqdLfH/abstract/?lang=pt>. Acesso em I7 de novembro de 202I.

NELSON, Loui Lord. Design and deliver: Planning and teaching using universal design for learning. Baltimore: Brookes Publishing, 2013.

NEVES, João Paulo Santos. Avaliação educacional e aprendizagem escolar. Jornal de Políticas Educacionais, v. I3, 2019. Disponível em: <https://revistas.ufpr.br/ jpe/article/view/67788>. Acesso em i7 de novembro de 2021.

PAIVA, Luciano Luan Gomes. Tecnologias digitais na educação musical: discussões emergentes. In: Conferência Regional Latino-americano de Educação Musical, Natal, 2017. Anais. UFRB: Natal, 2017. Disponível em:<http://abemeducacaomusical. com.br/conferencias/index.php/isme/2017/paper/view/2478>. Acesso em I7 de novembro de 202I.

PONTES, Idalina Amélia Mota. Atuação psicopedagógica no contexto escolar: manipulação, não; contribuição, sim. Revista Psicopedagogia, v. 27, n. 84, p. 417-427, 2010. Disponível em: 〈http://pepsic.bvsalud.org/scielo.php?script=sci_arttext\& pid= Soro384862010000300oII $>$. Acesso em I7 de novembro de 202I.

SILVA, Cícera Aparecida Rodrigues. Experimentos sonoros: uma proposta para a educação musical no Ensino Médio. 2020. I86f. Dissertação (Mestrado Profissional em Artes) Universidade Estadual Paulista "Júlio de Mesquita Filho", Instituto de Artes, São Paulo.

SOUZA, Larissa Negris. Arquitetura escolar, parâmetros de projeto e modalidades de aprendizagem. 2018. I8gf. Dissertação (Mestrado em Arquitetura, Tecnologia e Cidade), Universidade de Campinas, Campinas, 2018.

VANZELA, Alexsander; OLIVEIRA, Leida Calegário; CARVALHO, Marivaldo Aparecido. A psicopedagogia e o ensino musical. Música em Perspectiva, v. Io, n. I, 2017. 
Disponível em: $\langle$ https://revistas.ufpr.br/musica/article/view/51490〉. Acesso em 17 de novembro de 202I.

VERCELLI, Ligia de Carvalho Abões. O trabalho do psicopedagogo institucional. Revista Espaço Acadêmico, v. 12, n. 139, p. 71-76, 2012. Disponível em: $\langle$ http://periodicos.uem.br/ojs/index.php/EspacoAcademico/article/view/1728I . Acesso em i7 de novembro de 2021.

ZERBATO, Ana Paula; MENDES, Enicéia Gonçalves. Desenho universal para a aprendizagem como estratégia de inclusão escolar. Educação Unisinos, v. 22, n. 2, p. 147-155, 2018. Disponível em: <https://www.redalyc.org/jatsRepo/4496/ 449657611004/4496576iroo4.pdf $>$. Acesso em I7 de novembro de 2021. 